\title{
Recombinant ACE2 Expression is Required for SARS-CoV-2 to Infect Primary Human Endothelial Cells and Induce Inflammatory and Procoagulative Responses
}

Short Title: SARS-CoV-2 Infection of ECs Requires Recombinant ACE2 Expression

Jonas, Nascimento Conde ${ }^{1^{*}}$, William Schutt $^{1^{*}}$, Elena E. Gorbunova $^{1}$, Erich R. Mackow ${ }^{1}$

${ }^{\mathbf{1}}$ Department of Microbiology and Immunology, Stony Brook University, Stony Brook, NY

* Co-First Authors that contributed equally to this work with the order determined by the level of contribution to preparing the figures and by mutual agreement between co-first authors.

\section{Corresponding Author}

Erich R. Mackow, Ph.D. Professor

AAM Fellow

Department of Microbiology and Immunology

Renaissance School of Medicine

Life Sciences Rm 126

Stony Brook University,

Stony Brook, NY 11794-5222

Erich.Mackow@ stonybrook.edu

631-632-7014 


\begin{abstract}
SARS-CoV-2 causes COVID-19, an acute respiratory distress syndrome (ARDS) characterized by pulmonary edema, viral pneumonia, multiorgan dysfunction, coagulopathy and inflammation. SARSCoV-2 uses angiotensin-converting enzyme 2 (ACE2) receptors to infect and damage ciliated epithelial cells in the upper respiratory tract. In alveoli, gas exchange occurs across an epithelial-endothelial barrier that ties respiration to endothelial cell (EC) regulation of edema, coagulation and inflammation. How SARS-CoV-2 dysregulates vascular functions to cause ARDS in COVID-19 patients remains an enigma focused on dysregulated EC responses. Whether SARS-CoV-2 directly or indirectly affects functions of the endothelium remains to be resolved and critical to understanding SARS-CoV-2 pathogenesis and therapeutic targets. We demonstrate that primary human ECs lack ACE2 receptors at protein and RNA levels, and that SARS-CoV-2 is incapable of directly infecting ECs derived from pulmonary, cardiac, brain, umbilical vein or kidney tissues. In contrast, pulmonary ECs transduced with recombinant ACE2 receptors are infected by SARS-CoV-2 and result in high viral titers $\left(\sim 1 \times 10^{7} / \mathrm{ml}\right)$, multinucleate syncytia and EC lysis. SARS-CoV-2 infection of ACE2-expressing ECs elicits procoagulative and inflammatory responses observed in COVID-19 patients. The inability of SARSCoV-2 to directly infect and lyse ECs without ACE2 expression explains the lack of vascular hemorrhage in COVID-19 patients and indicates that the endothelium is not a primary target of SARSCoV-2 infection. These findings are consistent with SARS-CoV-2 indirectly activating EC programs that regulate thrombosis and endotheliitis in COVID-19 patients, and focus strategies on therapeutically targeting epithelial and inflammatory responses that activate the endothelium or initiate limited ACE2 independent EC infection.
\end{abstract}




\section{Importance}

SARS-CoV-2 infects pulmonary epithelial cells through ACE2 receptors and causes ARDS. COVID-19 causes progressive respiratory failure resulting from diffuse alveolar damage and systemic coagulopathy, thrombosis and capillary inflammation that tie alveolar responses to EC dysfunction. This has prompted theories that SARS-CoV-2 directly infects ECs through ACE2 receptors, yet SARS-CoV2 antigen has not been co-localized with ECs and prior studies indicate that ACE2 co-localizes with alveolar epithelial cells and vascular smooth muscle cells, not ECs. Here we demonstrate that primary human ECs derived from lung, kidney, heart, brain and umbilical veins require expression of recombinant ACE2 receptors in order to be infected by SARS-CoV-2. However, SARS-CoV-2 lytically infects ACE2-ECs and elicits procoagulative and inflammatory responses observed in COVID-19 patients. These findings suggest a novel mechanism of COVID-19 pathogenesis resulting from indirect EC activation, or infection of a small subset of ECs by an ACE2 independent mechanism, that transform rationales and targets for therapeutic intervention. 
SARS-CoV-2 predominantly infects the epithelium of upper and lower airways causing pulmonary pathology and $\operatorname{ARDS}^{(1)}$. COVID-19 is characterized by progressive respiratory failure resulting from diffuse alveolar damage, inflammatory infiltrates, endotheliitis and pulmonary and systemic coagulopathy forming obstructive microthrombi with multiorgan dysfunction ${ }^{(1-3)}$. Collectively these findings indicate that initial pulmonary epithelial infection leads to COVID-19 vasculopathy with featured alveolar endothelial cell (EC) dysfunction playing a key role in anomalous vascular leakage, coagulation and inflammation. In COVID-19 patients procoagulative responses are associated with altered von Willebrand factor (vWF) and thrombomodulin expression, and the induction of proinflammatory cytokines (IL1, IL6, TNF $\alpha$ ) that further implicate activation of the endothelium in myocarditis and vasculopathy ${ }^{(1-4)}$.

Despite coagulopathy and capillary inflammation in COVID-19 patients, it is unclear whether ECs are directly infected by SARS-CoV-2 or whether EC activation is an indirect response to primary alveolar epithelial cell damage and inflammatory responses ${ }^{(1-3)}$. SARS-CoV-2 infects cells by attaching to human ACE2 receptors ${ }^{(5-7)}$. Rationales for SARS-CoV-2 directly infecting ECs originated from prothrombotic findings, endotheliitis, protective ACE2 functions and reports that ECs express cellular ACE2 receptors ${ }^{(8-10)}$. However, several studies demonstrate that in the vasculature ACE2 is confined to the tunica media, co-localizing with smooth muscle actin, not the endothelium ${ }^{(11-14)}$. CDC analysis of COVID-19 patient tissues indicates that SARS-CoV-2 is detectable in airways, pneumocytes, alveolar macrophages and lymph nodes, but not in ECs or other extrapulmonary tissues ${ }^{(1)}$. In retrospect, there is minimal data supporting SARS-CoV-2 infection of ECs and no immunohistochemical studies demonstrating the co-localization of SARS-CoV-2 antigens with EC markers in pulmonary or renal tissues, which express ACE2 on adjacent epithelial cells. Nearly all studies reference electron microscopy data displaying two potential SARS-CoV-2 particles $^{(3,15)}$, that instead of virus have been implicated as being ER vesicles ${ }^{(16)}$. 
Nonetheless, pathologic findings in COVID-19 patients demonstrate the dysregulation of EC functions ${ }^{(17)}$, however, the mechanism(s) of endothelial damage and activation in SARS-CoV-2 directed coagulopathy and inflammation remain to be revealed ${ }^{(2,4)}$. Our initial studies were predicated on ACE2 receptors directing SARS-CoV-2 infection and dysregulation of normal EC functions. We critically analyzed SARS-CoV-2 infection of primary human ECs derived from lung, heart, kidney, brain and umbilical veins (S1-methods). Remarkably we found that SARS-CoV-2 failed to infect primary human ECs derived from any organ. In contrast to the complete infection of VeroE6 cells, no SARS-CoV-2 infected ECs were detected, by $\mathrm{N}$ or Spike antigen immunostaining, at any multiplicity of infection or plating cell density (Figure 1A). Consistent with this both ACE2 RNA and protein, found in VeroE6 and Calu3 cells, were undetectable in ECs (Figure 1B,C), and no viral progeny was detected in the supernatants of SARS-CoV-2 infected human ECs (1-3 dpi)(Figure 1G).

To determine whether SARS-CoV-2 infection of ECs is receptor restricted, we lentivirus transduced primary human pulmonary and brain ECs to express ACE2 and evaluated viral replication and protein expression. We found that expressing ACE2 in primary human ECs permitted SARS-CoV-2 to ubiquitously and productively infect ECs reaching viral titers of 1-3 x 10² (1-3 dpi) (Figure 1D,G)(S1methods). SARS-CoV-2 infection co-localized with ACE2 expressing ECs (Fig. 1E,F) and resulted in detectable $\mathrm{N}$ protein 4-6 hpi, and multinucleate syncytia and EC lysis 12-24 hpi (Figure 1D,F). Collectively, these findings demonstrate that primary human ECs lack ACE2 receptors required for SARS-CoV-2 infection, but express proteases essential for SARS-CoV-2 infection. These findings suggest that SARS-CoV-2 may cause procoagulative endotheliitis through indirect EC dysregulation mechanisms or as a result of ACE2 independent, or induction directed, infection of a small number of activated ECs.

The potential for damage, inflammation or activation to conditionally permit SARS-CoV-2 infection of a small EC subset ${ }^{(12,18,19)}$, prompted us to analyze cellular responses that may contribute to COVID-19 pathogenesis. We analyzed transcriptional responses of ACE2-expressing ECs to SARS- 
CoV-2 infection and found significant changes in mRNAs that regulate coagulation and inflammation from 6-24 hrs (S1-methods) including: 2-3-fold decreases in PAI-1, anti-thrombin and Factor VIII; and increases in tissue factor (24-fold), thrombomudulin (TM), 6-fold), vWF (3-fold), thrombin receptors (PAR1/3 3-fold), EGR-1 (37-fold), E-selectin (600-fold), IL-1 $\beta$ (28-fold), IL-6 (12-fold) and TNF $\alpha$ $\left(160\right.$-fold) ${ }^{(20,21)}$ (Figure 2A). SARS-CoV-2 selectively induced thrombomodulin in infected rACE2hPMECs, with TM internally co-localized with viral N protein (Figure 2B), suggesting the potential for SARS-CoV-2 to sequester a coagulation inhibiting EC surface receptor ${ }^{(20)}$. However, a comprehensive assessment of coagulation and inflammatory mediators in SARS-CoV-2 infected epithelial and endothelial cells is required to fully understand EC activation events and complex coagulation factor and inflammatory responses that can be therapeutically targeted.

Our findings indicate that the absence of ACE2 prevents SARS-CoV-2 infection of human ECs and suggests that ECs are not primary targets of SARS-CoV-2 infection in COVID-19 patients. Consistent with this, COVID-19 does not result in Ebola-like hemorrhagic disease that would likely result from lytic SARS-CoV-2 infection of ACE2-expressing ECs. The inability of SARS-CoV-2 to infect human ECs is supported by low ACE2 expression in the highly vascularized lower respiratory $\operatorname{tract}^{(24)}, \mathrm{CDC}$ and primary human EC infection findings ${ }^{(1,14,24)}$ and the presence of ACE2 in vascular smooth muscle and heart muscle cells ${ }^{(11,18,23,25)}$, but not the EC lining of vessels ${ }^{(12-14,23)}$. These findings support a secondary role of the endothelium, perhaps in response to epithelial cell damage and crosstalk, alveolar tissue factor/basement membrane exposure or inflammatory EC activation that directs a coagulative, endotheliitic state ${ }^{(1,3,17,22)}$.

Our findings do not address whether SARS-CoV-2 infection of pulmonary epithelial cells permits SARS-CoV-2 to selectively infect or activate ECs. In the course of these experiments we tested, but were unable to define, conditions that permitted SARS-CoV-2 infection of pulmonary ECs (addition of Angiotensin II, activating AMP kinase, hypoxia, TNF $\alpha$, IL-1 $\beta$, IL6, bradykinin, endothelin-1). However, it remains conceivable that COVID-19 epithelial cell or immune cell responses selectively 
activate the endothelium ${ }^{(2)}$ and permit a subset of ECs to be infected over time ${ }^{(19)}$. Reported EC heterogeneity in response to acute lung injury ${ }^{(19)}$ supports the potential for infection of a subset of ECs, and one report suggests that 1/250 ECs are ACE2 positive, and that both SARS-CoV-2 and influenza virus increase the number of ACE2 positive $\mathrm{ECs}^{(3)}$. Yet SARS-CoV-2 infection of ACE2 expressing ECs remains to be demonstrated in COVID-19 patients and is at odds with current findings and additional studies indicating that ECs lack ACE2 ${ }^{(12-14,23)}$.

Consistent with COVID-19 disease we found that SARS-CoV-2 infection of ECs induces procoagulative and inflammatory mediators ${ }^{(1-3,17,21)}$. Our finding that the coagulation initiator, tissue factor, is highly induced, whereas the coagulation inhibitor thrombomodulin is induced and may be sequestered within ECs, provide potential thrombotic mechanisms, while findings of induced cytokines and E-selectin are consistent with inflammation and endotheliitis ${ }^{(3,20,22,26)}$. These results rationalize a detailed analysis of EC expressed procoagulative and inflammatory factors and the potential role of targeting thrombomodulin, TNF $\alpha$ and E-selectin in resolving EC directed COVID-19 coagulation and inflammation $^{(3,4,20,26)}$. However, in the absence of EC infection, damage to alveolar epithelial cells may alone initiate coagulopathy through tissue factor, intra-alveolar fibrin deposition and common EC basement membrane exposure that triggers activation of the endothelium ${ }^{(22,27)}$. In COVID-19 patients, EC damage and activation responses are also likely to be exacerbated by impaired ACE2 activity that increases the severity of ARDS, AngII directed EC damage, bradykinin directed permeability and inflammation, and the loss of protective anti-inflammatory Ang 1-7 responses $^{(9,25,28-30)}$. Overall, our data suggests that SARS-CoV-2 is likely to indirectly dysregulate EC functions, and this explains the absence of an acute lytic infection of ECs, and the chronic vascular disease process that over time evolves into an aberrant prothrombotic endotheliitis in COVID-19 patients. These findings focus strategies on therapeutically targeting epithelial and inflammatory responses that activate the endothelium or initiate limited ACE2 independent EC infection. 

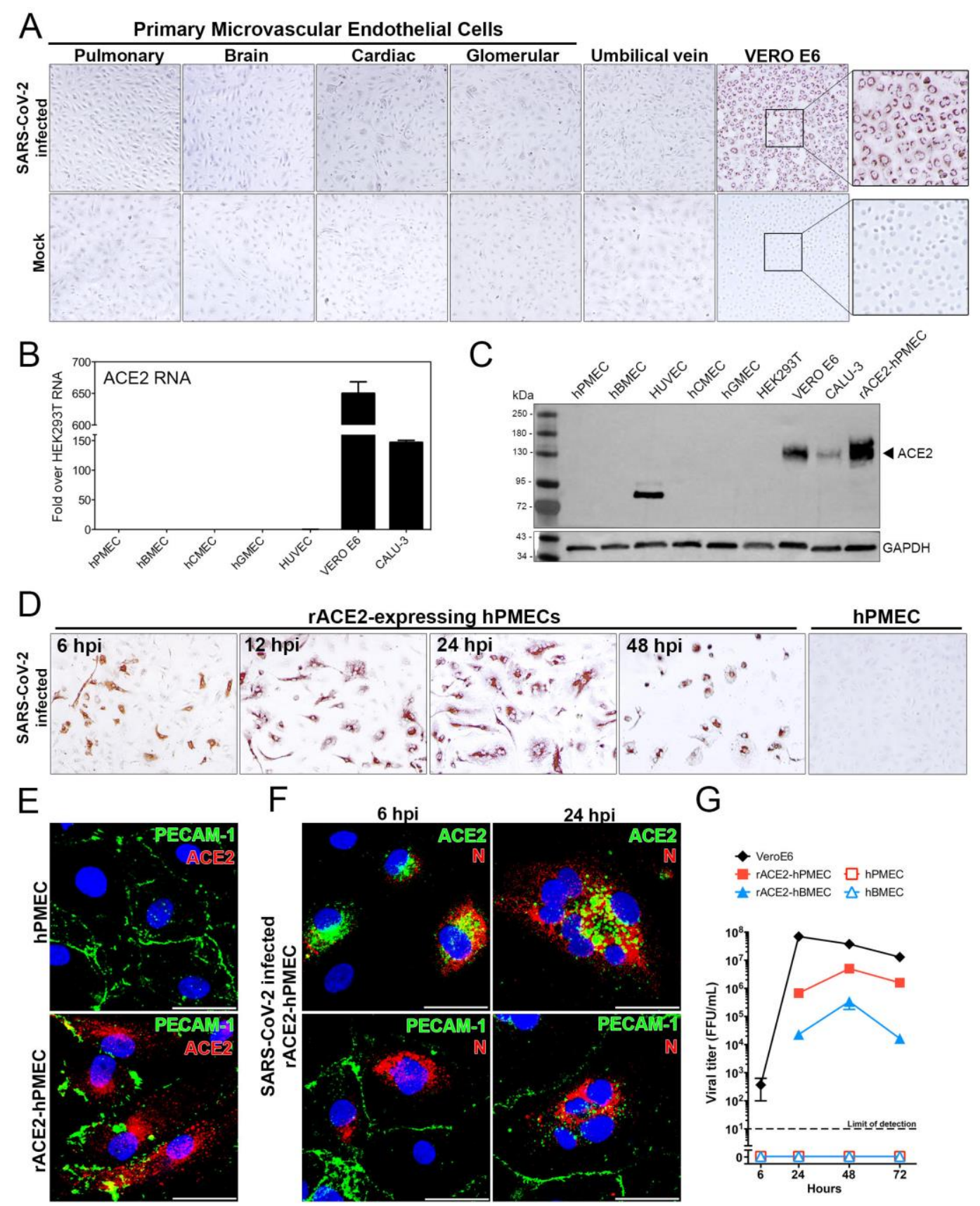

G

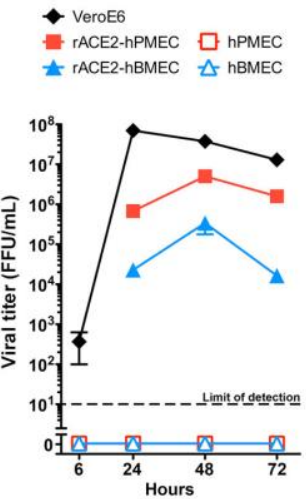

Figure 1 SARS-CoV-2 Fails to Infect Primary Human Endothelial Cells without rACE2 Expression. Primary human microvascular endothelial cells from pulmonary (hPMECs), brain (hBMECs), cardiac (HCMECs), glomerular (hGMECs) or umbilical vein (HUVECs), or VeroE6 cells were mock or SARS-CoV-2(strain WA) infected (MOI 10) and 24 hpi (A) immunoperoxidase stained for nucleocapsid protein. Primary human ECs, VeroE6, HEK293T and Calu3 cells were analyzed by (B) qRT-PCR for ACE2 mRNA, and (C) by Western Blot for expressed ACE2. HUVECs contain a potential ACE2 truncation lacking the N-terminal SARS-CoV-2 binding domain. (D) Primary human pulmonary ECs lentivirus transduced to express recombinant ACE2 were infected with SARS-CoV-2 (MOI 1) for 6-48 hpi. (E) ACE2-hPMECs or WT-hPMECs were immunoperoxidase stained for nucleocapsid protein. hPMECs or rACE2-hPMECs were analyzed by IFA for the EC marker PECAM-1 and ACE2. (F) Following SARS-CoV-2 infection, rACE2-hPMECs were analyzed by IFA for coexpressed ACE2 and nucleocapsid protein (N) or PECAM-1 expression. Bars represent $50 \mu \mathrm{m}$.

(G) Supernatants of Sars-CoV-2 infected (MOI 1) WT hPMECs, hBMECs, rACE2-hPMECs, rACE2hBMECs and VeroE6 cells were titered 2-72 hpi (Limit of detection <10 FFUs/ml). 


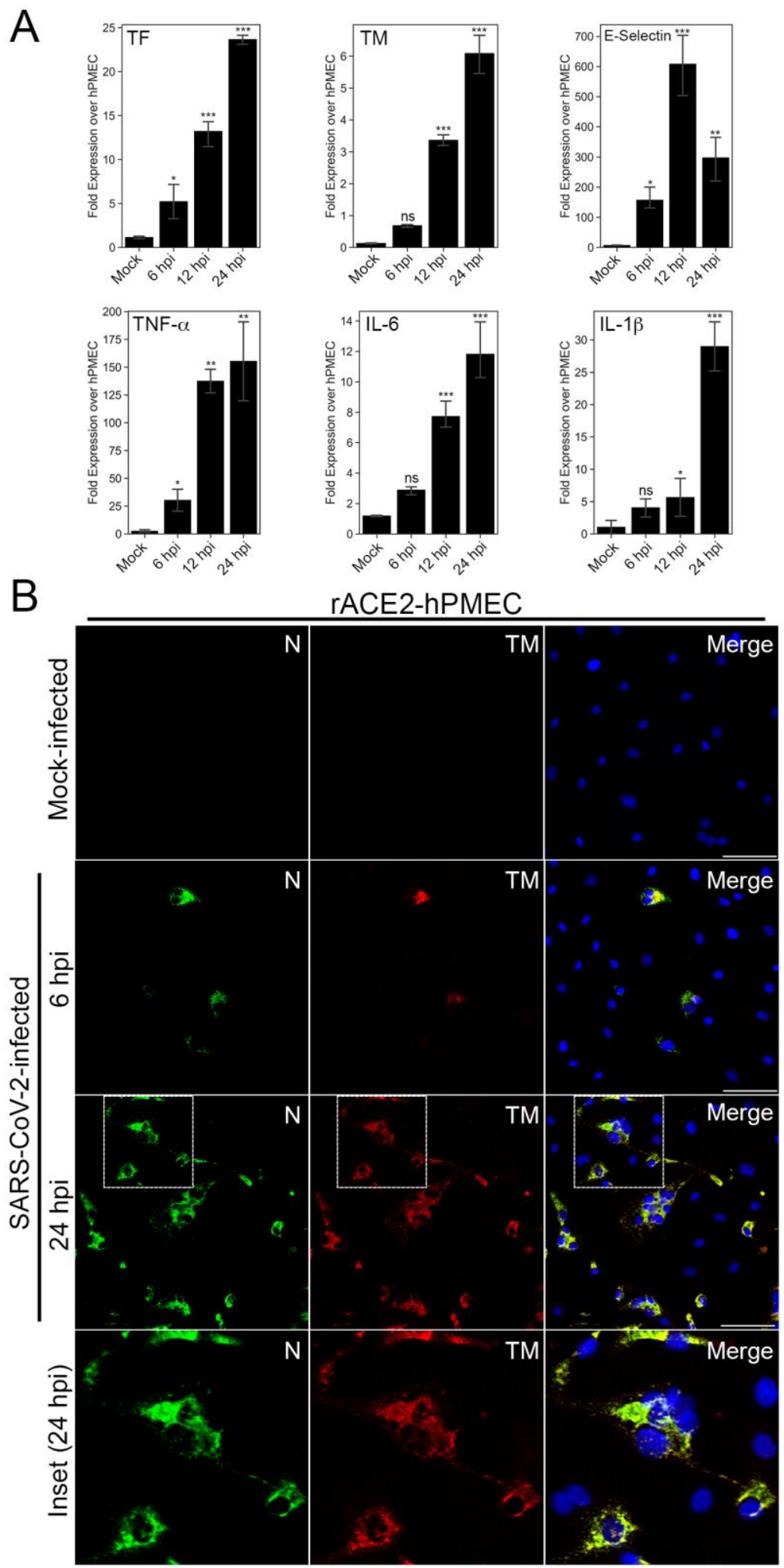

Figure 2 Recombinant ACE2 Expressing ECs Elicit Procoagulation and Inflammatory Responses. hPMECs expressing recombinant ACE2 (hPMEC-rACE2) were synchronously infected with SARSCoV-2 and analyzed by qRT-PCR for changes in the mRNA levels of coagulation and inflammatory responses 6-24 hpi. (A) Levels of tissue factor (TF), thrombomodulin (TM), Tumor necrosis factor $\alpha$ (TNF $\alpha$ ) Interleukin 6 (IL-6), IL-1 $\beta$ and E-selectin were found to increase dramatically in SARS-CoV-2 infected ECs. (B) The induction of TM in SARS-CoV-2 infected rACE2-hBMECs (MOI 1) was monitored by IFA of viral nucleocapsid (N) and cellular expressed thrombomodulin (TM) from 6-24 hpi. 
Supplemental Material: The methods used within the studies describing cells, virus, SARS-CoV-2 infection, ACE2 lentivirus transduction, qRT-PCR analysis, Western Blotting, confocal Immunofluorescense and statistical analysis are presented in the supplemental section $\mathrm{S} 1$.

Acknowledgements: This work was supported by a SARS-CoV-2 Seed Grant from Stony Brook University and funding from the Mathers Foundation and the National Institutes of Health NIAID R01AI12901004, R21AI13173902, R21AI15237201. We thank Ken Kaushansky, Berhane Ghebrehiwit and the SARS-CoV-2 SBU research group of Patrick Hearing, Janet Hearing, Nancy Reich and Hwan Kim for helpful input, discussions and critical review of the manuscript.

Competing Interests: The authors have no financial, personal or professional interests that could be construed to have influenced the work.

\section{References}

1. Martines RB, Ritter JM, Matkovic E, Gary J, Bollweg BC, Bullock H, Goldsmith CS, Silva-Flannery L, Seixas JN, Reagan-Steiner S, Uyeki T, Denison A, Bhatnagar J, Shieh WJ, Zaki SR, Group C-PW. 2020. Pathology and Pathogenesis of SARS-CoV-2 Associated with Fatal Coronavirus Disease, United States. Emerg Infect Dis 26:2005-2015.

2. Teuwen LA, Geldhof V, Pasut A, Carmeliet P. 2020. COVID-19: the vasculature unleashed. Nat Rev Immunol 20:389-391.

3. Ackermann M, Verleden SE, Kuehnel M, Haverich A, Welte T, Laenger F, Vanstapel A, Werlein C, Stark H, Tzankov A, Li WW, Li VW, Mentzer SJ, Jonigk D. 2020. Pulmonary Vascular Endothelialitis, Thrombosis, and Angiogenesis in Covid-19. N Engl J Med 383:120-128.

4. Yau JW, Teoh H, Verma S. 2015. Endothelial cell control of thrombosis. BMC Cardiovasc Disord 15:130.

5. Hoffmann M, Kleine-Weber H, Schroeder S, Kruger N, Herrler T, Erichsen S, Schiergens TS, Herrler G, Wu NH, Nitsche A, Muller MA, Drosten C, Pohlmann S. 2020. SARS-CoV-2 Cell Entry Depends on ACE2 and TMPRSS2 and Is Blocked by a Clinically Proven Protease Inhibitor. Cell 181:271-280 e278.

6. Wang Q, Zhang Y, Wu L, Niu S, Song C, Zhang Z, Lu G, Qiao C, Hu Y, Yuen KY, Wang Q, Zhou H, Yan J, Qi J. 2020. Structural and Functional Basis of SARS-CoV-2 Entry by Using Human ACE2. Cell doi:10.1016/j.cell.2020.03.045.

7. Lukassen S, Chua RL, Trefzer T, Kahn NC, Schneider MA, Muley T, Winter H, Meister M, Veith C, Boots AW, Hennig BP, Kreuter M, Conrad C, Eils R. 2020. SARS-CoV-2 receptor ACE2 and TMPRSS2 are primarily expressed in bronchial transient secretory cells. EMBO J doi:10.15252/embj.20105114:e105114.

8. Yu X, Lin Q, Qin X, Ruan Z, Zhou J, Lin Z, Su Y, Zheng J, Liu Z. 2016. ACE2 Antagonizes VEGFa to Reduce Vascular Permeability During Acute Lung Injury. Cell Physiol Biochem 38:1055-1062.

9. Zhang YH, Zhang YH, Dong XF, Hao QQ, Zhou XM, Yu QT, Li SY, Chen X, Tengbeh AF, Dong B, Zhang Y. 2015. ACE2 and Ang-(1-7) protect endothelial cell function and prevent early atherosclerosis by inhibiting inflammatory response. Inflamm Res 64:253-260.

10. Hamming I, Timens W, Bulthuis ML, Lely AT, Navis G, van Goor H. 2004. Tissue distribution of ACE2 protein, the functional receptor for SARS coronavirus. A first step in understanding SARS pathogenesis. J Pathol 203:631-637.

11. Patel VB, Zhong JC, Fan D, Basu R, Morton JS, Parajuli N, McMurtry MS, Davidge ST, Kassiri Z, Oudit GY. 2014. Angiotensin-converting enzyme 2 is a critical determinant of angiotensin II-induced loss of vascular smooth muscle cells and adverse vascular remodeling. Hypertension 64:157-164.

12. Soler MJ, Ye M, Wysocki J, William J, Lloveras J, Batlle D. 2009. Localization of ACE2 in the renal vasculature: amplification by angiotensin II type 1 receptor blockade using telmisartan. Am J Physiol Renal Physiol 296:F398-405.

13. Zulli A, Burrell LM, Buxton BF, Hare DL. 2008. ACE2 and AT4R are present in diseased human blood vessels. Eur J Histochem 52:39-44. 
14. Ziegler CGK, Allon SJ, Nyquist SK, Mbano IM, Miao VN, Tzouanas CN, Cao Y, Yousif AS, Bals J, Hauser BM, Feldman J, Muus C, Wadsworth MH, 2nd, Kazer SW, Hughes TK, Doran B, Gatter GJ, Vukovic M, Taliaferro F, Mead BE, Guo Z, Wang JP, Gras D, Plaisant M, Ansari M, Angelidis I, Adler H, Sucre JMS, Taylor CJ, Lin B, Waghray A, Mitsialis V, Dwyer DF, Buchheit KM, Boyce JA, Barrett NA, Laidlaw TM, Carroll SL, Colonna L, Tkachev V, Peterson CW, Yu A, Zheng HB, Gideon HP, Winchell CG, Lin PL, Bingle CD, Snapper SB, Kropski JA, Theis FJ, et al. 2020. SARS-CoV-2 Receptor ACE2 Is an Interferon-Stimulated Gene in Human Airway Epithelial Cells and Is Detected in Specific Cell Subsets across Tissues. Cell 181:1016-1035 e1019.

15. Varga Z, Flammer AJ, Steiger P, Haberecker M, Andermatt R, Zinkernagel AS, Mehra MR, Schuepbach RA, Ruschitzka F, Moch H. 2020. Endothelial cell infection and endotheliitis in COVID-19. Lancet 395: 1417-1418.

16. Goldsmith CS, Miller SE, Martines RB, Bullock HA, Zaki SR. 2020. Electron microscopy of SARS-CoV2: a challenging task. Lancet 395:e99.

17. Wang J, Saguner AM, An J, Ning Y, Yan Y, Li G. 2020. Dysfunctional Coagulation in COVID-19: From Cell to Bedside. Adv Ther 37:3033-3039.

18. Zhang R, Wu Y, Zhao M, Liu C, Zhou L, Shen S, Liao S, Yang K, Li Q, Wan H. 2009. Role of HIF1alpha in the regulation ACE and ACE2 expression in hypoxic human pulmonary artery smooth muscle cells. Am J Physiol Lung Cell Mol Physiol 297:L631-640.

19. Niethamer TK, Stabler CT, Leach JP, Zepp JA, Morley MP, Babu A, Zhou S, Morrisey EE. 2020. Defining the role of pulmonary endothelial cell heterogeneity in the response to acute lung injury. Elife 9.

20. Ito T, Thachil J, Asakura H, Levy JH, Iba T. 2019. Thrombomodulin in disseminated intravascular coagulation and other critical conditions-a multi-faceted anticoagulant protein with therapeutic potential. Crit Care 23:280.

21. Hottz ED, Azevedo-Quintanilha IG, Palhinha L, Teixeira L, Barreto EA, Pao CRR, Righy C, Franco S, Souza TML, Kurtz P, Bozza FA, Bozza PT. 2020. Platelet activation and platelet-monocyte aggregate formation trigger tissue factor expression in patients with severe COVID-19. Blood 136:1330-1341.

22. Connors JM, Levy JH. 2020. COVID-19 and its implications for thrombosis and anticoagulation. Blood 135:2033-2040.

23. Ferrario CM, Jessup J, Chappell MC, Averill DB, Brosnihan KB, Tallant EA, Diz DI, Gallagher PE. 2005. Effect of angiotensin-converting enzyme inhibition and angiotensin II receptor blockers on cardiac angiotensin-converting enzyme 2. Circulation 111:2605-2610.

24. Hou YJ, Okuda K, Edwards CE, Martinez DR, Asakura T, Dinnon KH, 3rd, Kato T, Lee RE, Yount BL, Mascenik TM, Chen G, Olivier KN, Ghio A, Tse LV, Leist SR, Gralinski LE, Schafer A, Dang H, Gilmore R, Nakano S, Sun L, Fulcher ML, Livraghi-Butrico A, Nicely NI, Cameron M, Cameron C, Kelvin DJ, de Silva A, Margolis DM, Markmann A, Bartelt L, Zumwalt R, Martinez FJ, Salvatore SP, Borczuk A, Tata PR, Sontake V, Kimple A, Jaspers I, O'Neal WK, Randell SH, Boucher RC, Baric RS. 2020. SARS-CoV-2 Reverse Genetics Reveals a Variable Infection Gradient in the Respiratory Tract. Cell 182:429-446 e414.

25. Ocaranza MP, Jalil JE. 2012. Protective Role of the ACE2/Ang-(1-9) Axis in Cardiovascular Remodeling. Int J Hypertens 2012:594361.

26. Culmer DL, Dunbar ML, Hawley AE, Sood S, Sigler RE, Henke PK, Wakefield TW, Magnani JL, Myers DD, Jr. 2017. E-selectin inhibition with GMI-1271 decreases venous thrombosis without profoundly affecting tail vein bleeding in a mouse model. Thromb Haemost 117:1171-1181.

27. Wang L, Bastarache JA, Wickersham N, Fang X, Matthay MA, Ware LB. 2007. Novel role of the human alveolar epithelium in regulating intra-alveolar coagulation. Am J Respir Cell Mol Biol 36:497-503.

28. Jia H. 2016. Pulmonary Angiotensin-Converting Enzyme 2 (ACE2) and Inflammatory Lung Disease. Shock 46:239-248.

29. Patel VB, Lezutekong JN, Chen X, Oudit GY. 2017. Recombinant Human ACE2 and the Angiotensin 1-7 Axis as Potential New Therapies for Heart Failure. Can J Cardiol 33:943-946.

30. Sodhi CP, Wohlford-Lenane C, Yamaguchi Y, Prindle T, Fulton WB, Wang S, McCray PB, Jr., Chappell M, Hackam DJ, Jia H. 2018. Attenuation of pulmonary ACE2 activity impairs inactivation of des$\operatorname{Arg}(9)$ bradykinin/BKB1R axis and facilitates LPS-induced neutrophil infiltration. Am J Physiol Lung Cell Mol Physiol 314:L17-L31. 
bioRxiv preprint doi: https://doi.org/10.1101/2020.11.10.377606; this version posted November 11, 2020. The copyright holder for this preprint (which was not certified by peer review) is the author/funder. All rights reserved. No reuse allowed without permission. 


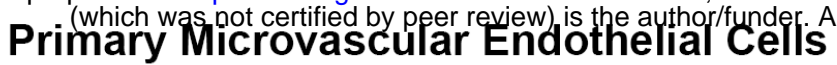

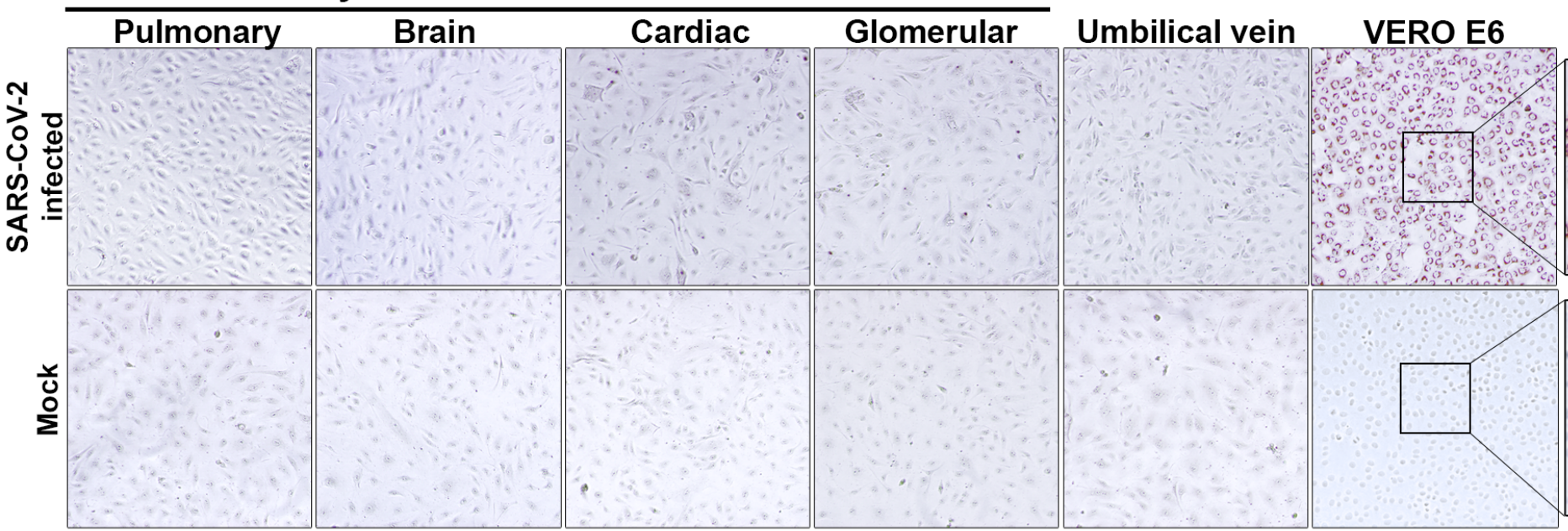

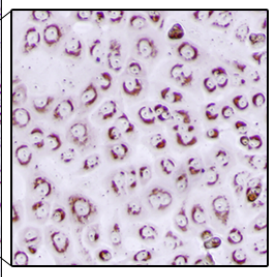

B
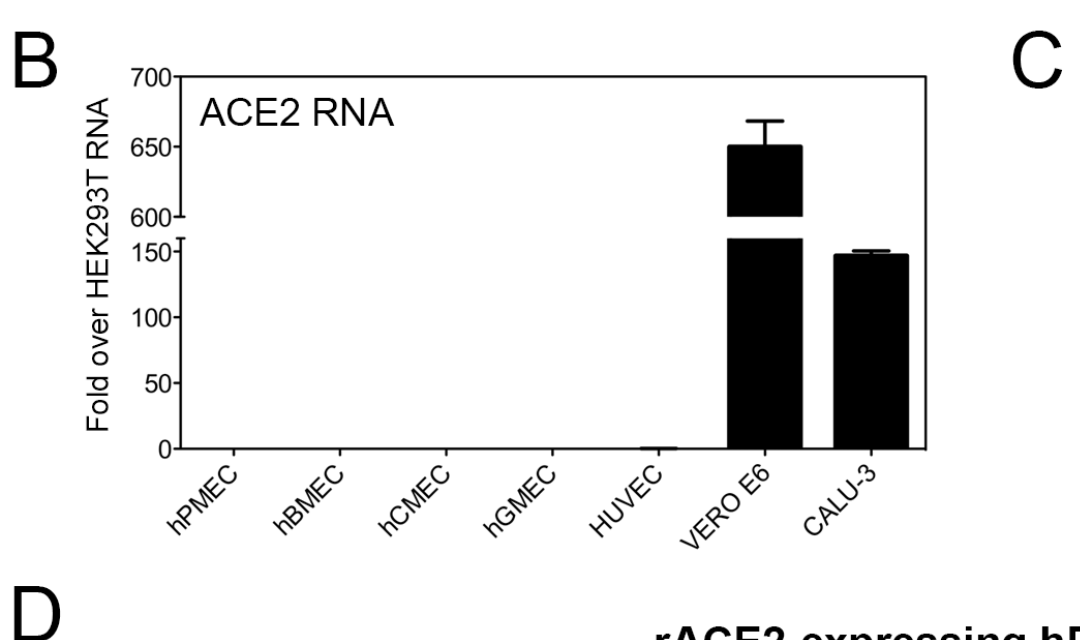
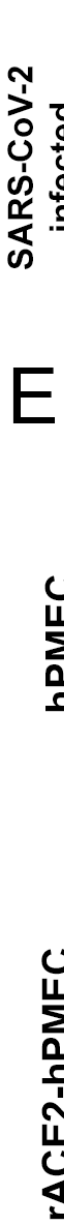

rACE2-expressing hPMECs

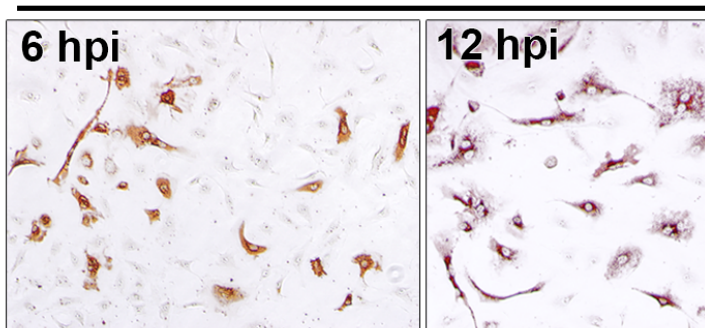

F

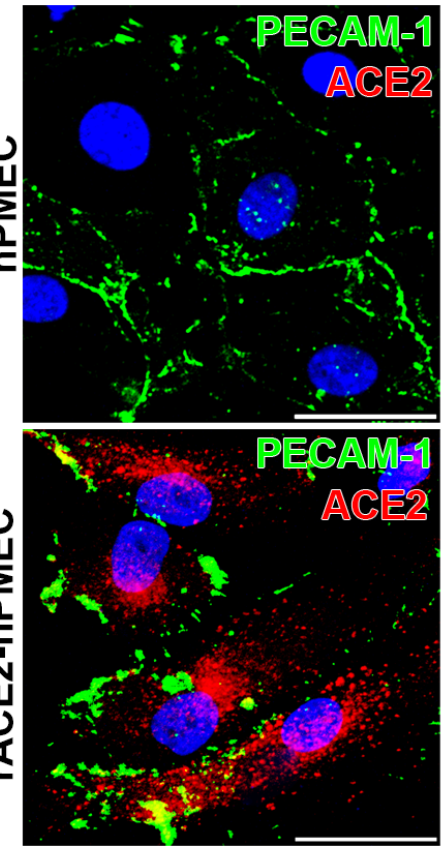

$6 \mathrm{hpi}$

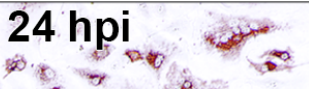

$x_{\infty}+20$

48 ḥpi : :

$4 \quad 0 \quad$

\section{G}

hPMEC

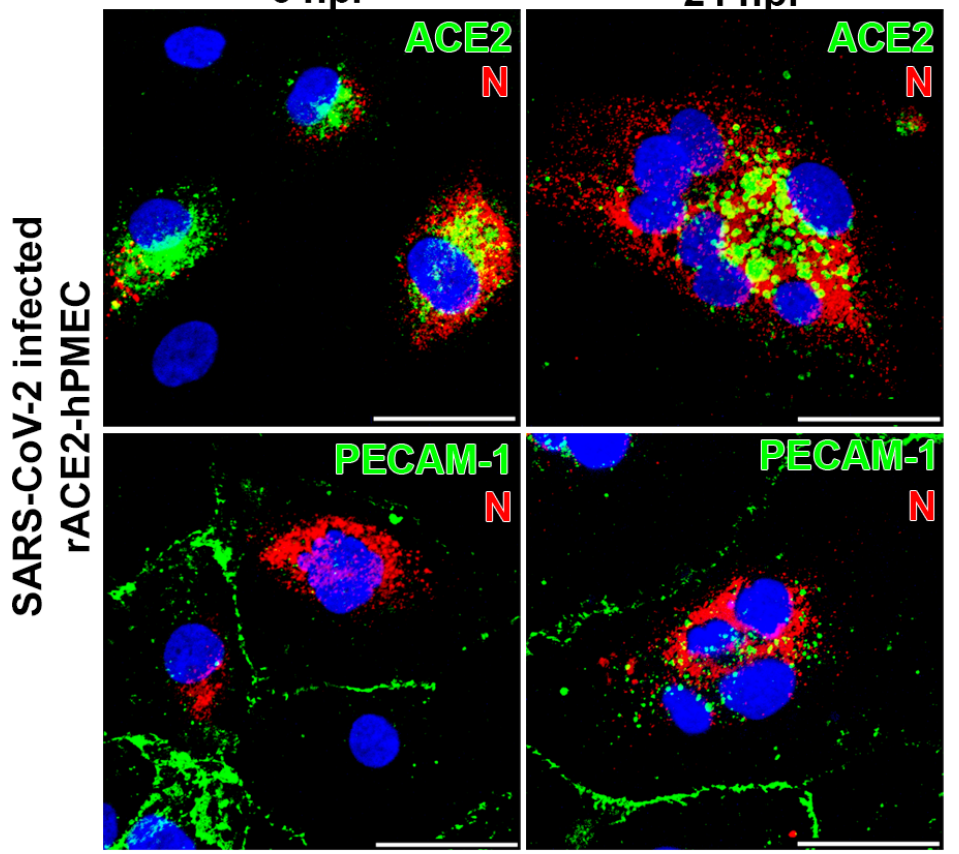

$\sim$ VeroE6
- rACE2-hPMEC $\square$ hPMEC
$\sim$ rACE2-hBMEC $\quad-$ hBMEC

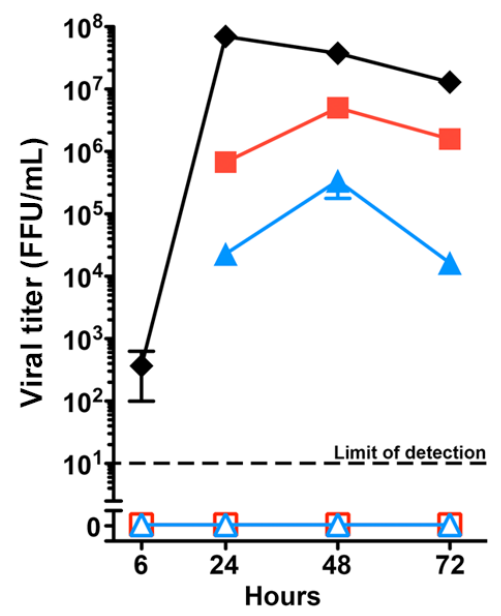


bioRxiv preprint o $\mathrm{d}:$ https://dojigrg/10.1101/2020.11.10.377606; this version posted November 11,2020 . The copyrightholder for this preprint

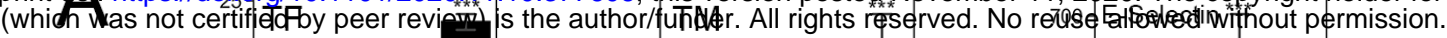
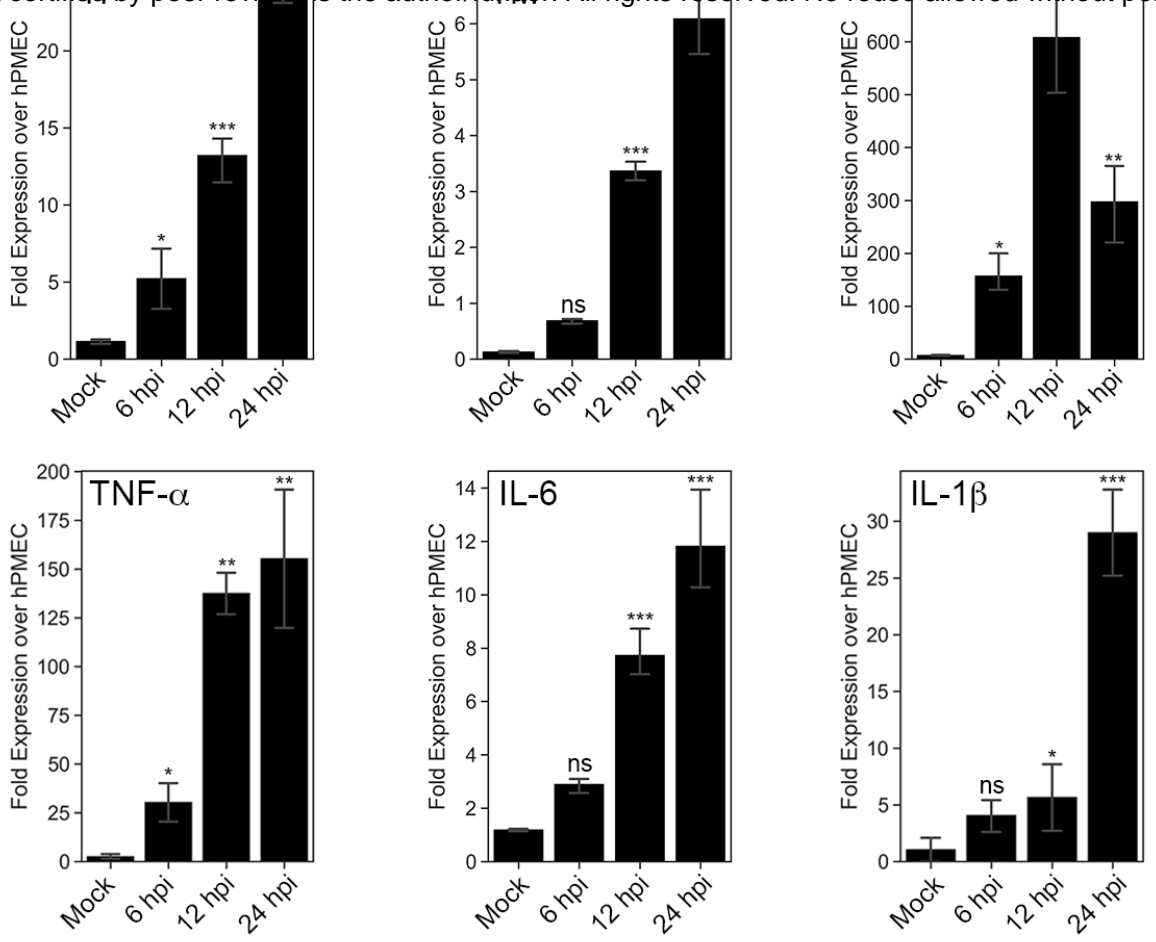

B

rACE2-hPMEC

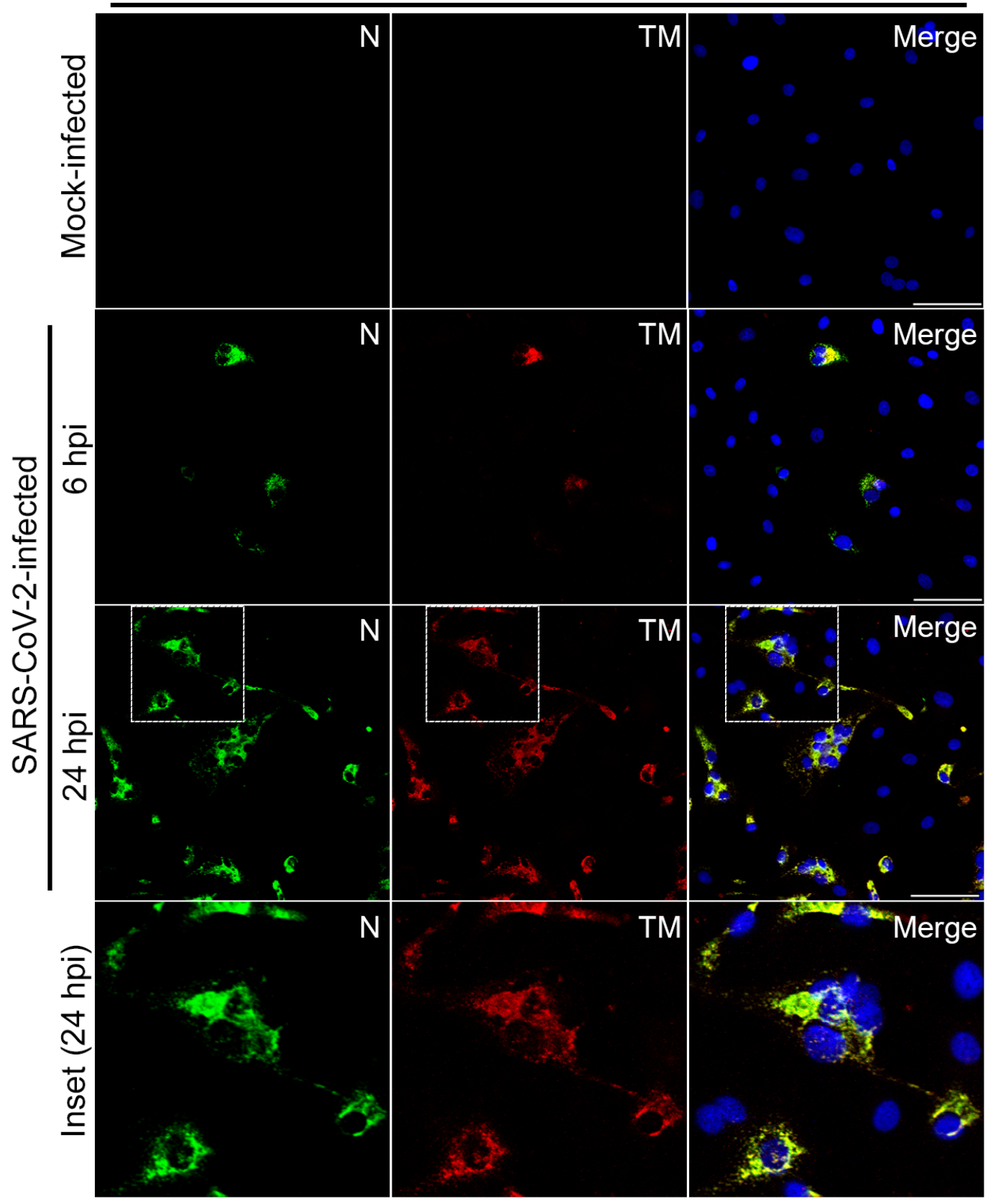

